\title{
Foreign Body Inflammatory Response following Rotator Cuff Repair with Biologic Scaffold Augmentation
}

\author{
William J Hill ${ }^{*}$, Ahmad Fashandi² ${ }^{2}$ d David R Diduch ${ }^{2}$ \\ ${ }^{1}$ College of Medicine, Howard University, USA \\ ${ }^{2}$ Department of Orthopaedic Surgery, University of Virginia, USA
}

\begin{abstract}
Arthroscopic rotator cuff repair with scaffold augmentation is used to produce a solid construct and decrease the probability of suture pull out. This is achieved biomechanically through redistributing the forces on the healing tendon and unloading forces onto the scaffold. Scaffolds provide a biomechanical advantage in outcomes of rotator cuff repairs by decreasing repair failures. This therapeutic advantage may be diminished or voided by a patient's immunologic response to the scaffold. This case report highlights how absorbable polymers in scaffolds can cause a foreign body inflammatory response, which can result in symptoms of pain and swelling of the affected joint. If a foreign body inflammatory response is suspected in a patient, arthroscopic debridement and scaffold removal should be performed. Symptoms will likely resolve and not reoccur.
\end{abstract}

\section{Introduction}

The etiology of rotator cuff tears (RCTs) can be divided into traumatic and degenerative causes. Though the etiologies of tears may differ the treatment options are the same. The factor which changes the treatment algorithm irrespective of etiology is size of the tear. The treatment of RCTs has evolved over the years. This evolution has been driven by the goal of achieving improved surgical outcomes and minimizing re-tearing rates [1]. Though there is not a consensus of what repair lifespans are, there is agreement that repairs with a solid construct fail less often and produce better outcomes [2-7]. The use of grafts to repair torn rotator cuffs include: tendon transfers from latissimus dorsi and pectoralis major and fascia lata autografts. In order to increase healing and tendon bone fixation scaffold implants have been incorporated in large rotator cuff repairs (RCR) [1]. Augmentation with the use of scaffolds allow for the load placed on the healing tendon to be redistributed onto the scaffold [1].

\section{Case report}

A 49-year-old man presented to clinic with ongoing right shoulder pain and weakness. A MRI was ordered which revealed a full-thickness tear of the right supraspinatus and anterior portion of the right infraspinatus. The patient subsequently failed non-operative treatment and elected to proceed with operative intervention secondary to persistent pain and weakness. During the diagnostic arthroscopy no pathology was noted with the biceps tendon, labrum, or articular cartilage. The subscapularis tendon was intact. The supraspinatus tendon was torn and retracted beneath the acromion to the level of the glenoid and the anterior fibers of the infraspinatus were torn as well. The tear pattern was " $\mathrm{L}$ shaped' and residual tissue was friable and of poor quality. Subsequently, the undersurface of the acromion was debrided up to the anterior and lateral margins and rotator cuff footprint was prepared for repair. The cuff repair was performed using the First Pass to pass a series of side to side margin convergence sutures which were then tied. A combination of two margin convergence stitches were utilized to close the horizontal rent in the rotator cuff followed by two $4.5 \mathrm{~mm}$ double loaded anchors for medial row fixation.
Given the nature of the tissue and amount of retraction the repair was then augmented by a implanted Tornier BioFiber collagen matrix patch scaffold, Alexandria, VA, (biofiber)and subsequently affixed to two $5.5 \mathrm{~mm}$ lateral row knotless anchors (Figure 1A, B).

Approximately 4 months after the repair the patient presented to clinic with shoulder effusions, pain, and warmth about the shoulder. His clinical presentation persisted for 8 months with several shoulder aspirations to rule out septic arthritis during this period - each time with elevated white blood cells counts above normal but below the threshold for septic arthritis. He was monitored and eventually each of these intermittent flares would spontaneously resolve. The patient's final aspirate prior to irrigation and debridement yielded 33,000 white blood cells and given the continued symptoms surgical intervention was recommended.

A preoperative MRI was obtained which revealed tendinopathy of the long head of his biceps tendon with fluid tracking down through the tendon sheath and significant synovitis throughout the subacromial space and glenohumeral joint (Figure 1C, D). No abscess or fluid collection was identified.

During diagnostic arthroscopy rotator cuff repair failure was noted and diffuse friable hyperemic tissue throughout the shoulder joint was identified, especially within the rotator interval and subacromial space. Multiple synovial biopsies were taken for pathologic evaluation as well as a specimen for culture.

While performing the extensive debridement of hyperemic tissues and inspecting the rotator cuff, the previously implanted biofiber had completely disassociated from the repair site and had not integrated

Correspondence to: William J. Hill, College of Medicine, Howard University, 520 W Street NW, Washington, D.C. 20059, USA, Tel:757-592-3097; E-mail: William.hill.med@gmail.com

Received: March 13, 2018; Accepted: March 19, 2018; Published: March 30 2018 


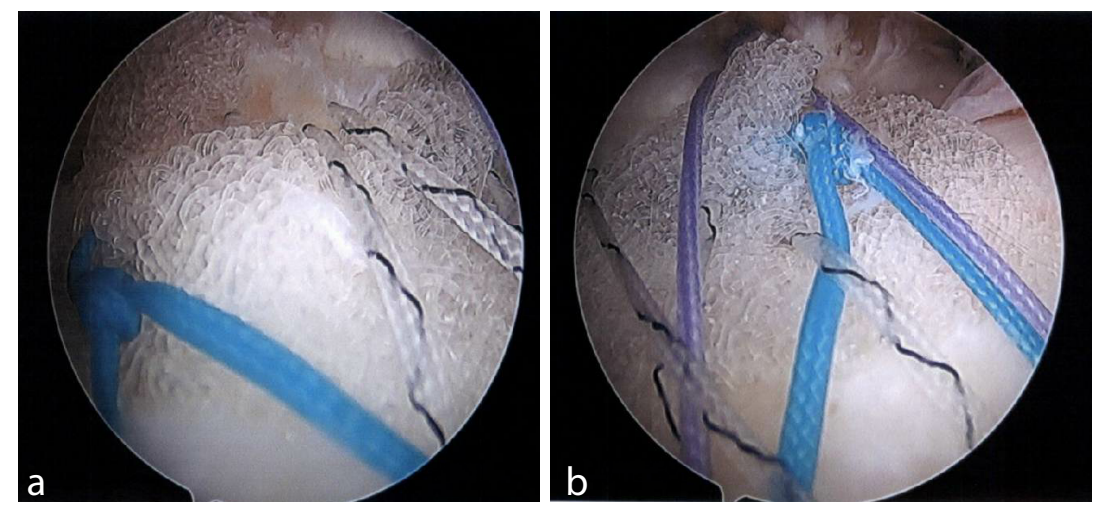

Figure 1. A, B show from the lateral portal is the biofiber scaffold being incorporated into the tendon attachment of the greater tuberosity.
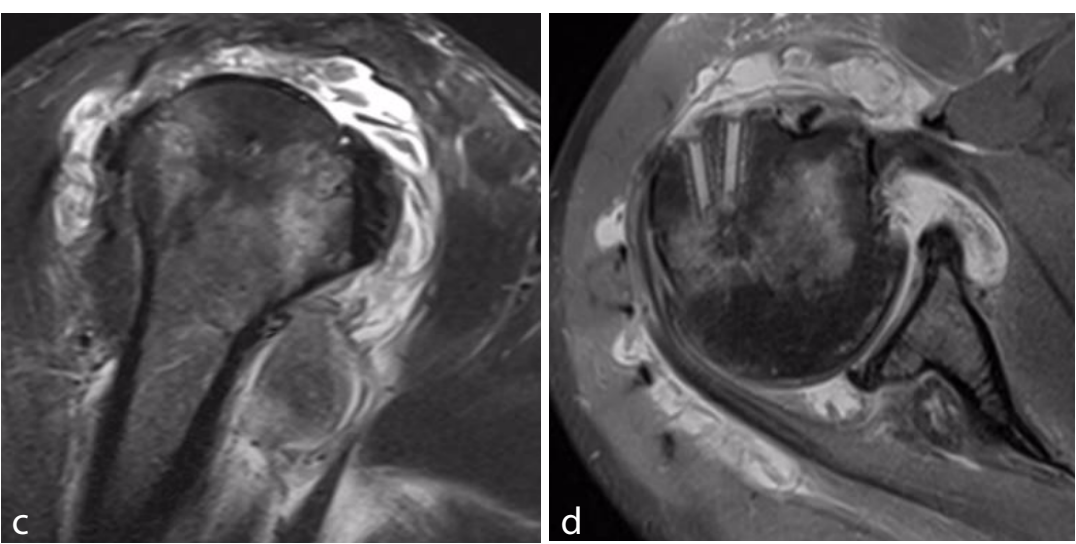

Figure 1. C, D show oblique coronal and sagittal MRI images of inflammatory changes/diffuse synovitis involving the glenohumeral joint and subacromial space.
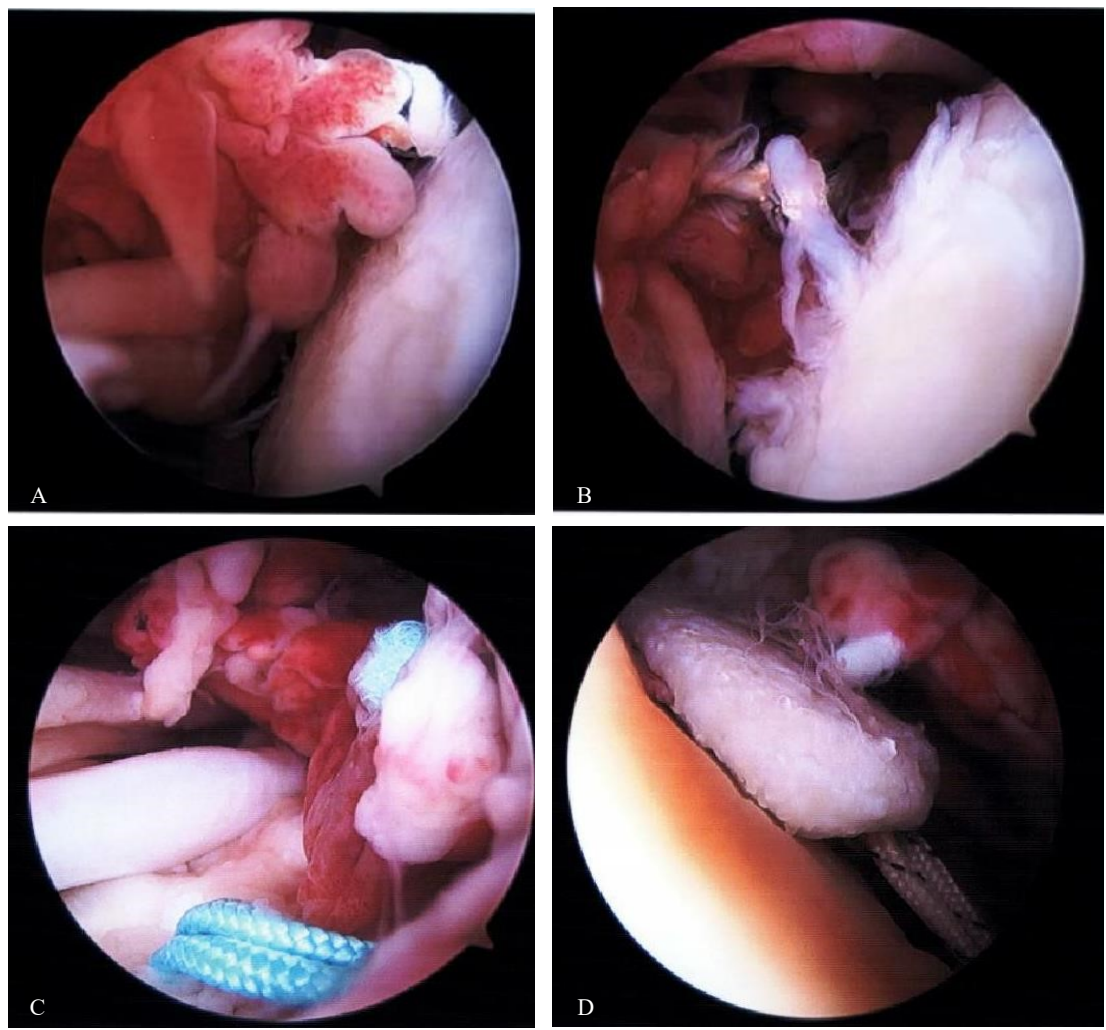

Figure 2. A-C Arthroscopic views show significant inflammatory response and retained sutures from posterior (A, B) and lateral (C) portals. D shows the inflammatory response encasing a remnant of the patch during arthroscopic removal from the lateral portal. 
into his native tissue. Additionally, the patch appeared to have fragmented into multiple pieces and was encapsulated in inflamed, friable appearing granulation tissue (Figure 2). We took an extended period of time to identify these fragments of the patch and removed them all in their entirety. We identified the biceps tendon sheath which was indeed quite inflamed and hyperemic with hypertrophic appearance. The tendon sheath was opened with additional fragments of the biofiber identified therein.

Pathology was consistent with intraoperative findings, noting inflamed synovial tissue and foreign body giant cell response. No bacteria were identified, and the culture remained negative after 14 days of growth.

\section{Discussion}

Giant cell inflammatory response in rotator cuff repairs (RCR) using scaffolds has been noted in the literature. Though this phenomenon is known to occur, it is quite rare. There has not been extensive human studies on the outcomes of rotator cuff tendon scaffolds. The scaffolds that are used in rotator cuff repairs (RCR) are composed of synthetic, biologic or hybrid materials.1 These scaffolds aim to reduce re-tear probability as a result of suture pullout at the attachment sites. Human skin derived scaffolds form the most stable constructs, followed by porcine and bovine skins, and small intestine submucosa derived scaffolds producing the weakest [1]. These aforementioned scaffolds are examples of extracellular matrix grafts. Acellular dermal human and porcine grafts have been reported to cause foreign body giant cell reactions [8-18]. Synthetic grafts, such as Poly-L-lactic acid (PLLA), polyactide-co-glycolic acid (PLGA), and polyglycolic acid (PGA), have also been found to evoke local foreign body giant cell reactions [1]. It has been thought that this response will subside as the scaffold degrades. Biofiber, collagen biologic scaffold, is composed of poly-4-hydroxybutyrate (P4HB) [19]. It was found to be biocompatible in animal studies. This is evidence that any absorbable polymer can generate a foreign body inflammatory response. These studies may translate mechanically in humans but the biocompatibility is not known until years after. According to the Clinical Trial Post-Market Observational Study there was one retear in the trial cohort and four adverse reactions [20]. The adverse reactions included: shoulder abscess and suspected septic arthritis, acute ischemic stroke, deep vein thrombosis, and superficial clot in the mid left basilic vein. These events were not attributed to the biofiber scaffold. Though foreign body giant cell reactions have been reported in synthetic scaffolds, there is no literature identifying this occurring with Tornier Biofiber scaffold augmentation. This case report aims to illustrate that tendon scaffolds can fail not only because of anatomical stress but also by immunologic processes. If an inflammatory response occurs debridement and removal of the scaffold may be warranted in order to resolve patients' symptoms. Since debridement of the shoulder and removal of the scaffold, the patient has not experienced further pain or swelling. Weakness is still present and a reverse total shoulder arthroplasty may be needed in the future. This is the first report of a giant cell inflammatory response to biologic scaffolds in the literature.

\section{References}

1. Chuang PJ, Zhang X, Boushell MK, Levine WN, Lu HH (2014) Basic science of Implant in Sports Medicine. In DeLee \& Drez's Orthopaedic Sports Medicine (4th ed.)

2. Williams GR Jr, Rockwood CA Jr, Bigliani LU, Iannotti JP, Stanwood W (2004) Rotator cuff tears: why do we repair them? J Bone Joint Surg Am 86-86A: 2764-76. [Crossref]

3. Galatz LM, Griggs S, Cameron BD, Iannotti JP (2001) Prospective longitudinal analysis of postoperative shoulder function: a ten-year follow-up study of full-thickness rotator cuff tears. J Bone Joint Surg Am 83-A: 1052-1056.[Crossref]

4. Gazielly DF, Gleyze P, Montagnon C (1994) Functional and anatomical results after rotator cuff repair. Clin Orthop Relat Res 43-53. [Crossref]

5. Gerber C, Fuchs B, Hodler J (2000) The results of repair of massive tears of the rotator cuff. J Bone Joint Surg Am 82: 505-515. [Crossref]

6. Harryman DT 2nd, Mack LA, Wang KY, Jackins SE, Richardson ML, et al. (1991) Repairs of the rotator cuff. Correlation of functional results with integrity of the cuff. $J$ Bone Joint Surg Am 73: 982-989. [Crossref]

7. Galatz LM, Ball CM, Teefey SA, Middleton WD, Yamaguchi K (2004) The outcome and repair integrity of completely arthroscopically repaired large and massive rotator cuff tears. J Bone Joint Surg Am 86-A: 219-224. [Crossref]

8. Iannotti JP, Codsi MJ, Kwon YW, Derwin K, Ciccone J, et al. (2006) Porcine small intestine submucosa augmentation of surgical repair of chronic two-tendon rotator cuff tears: a randomized, controlled trial. J Bone Joint Surg Am 88: 1238-1244. [Crossref]

9. Sclamberg SG, Tibone JE, Itamura JM, Kasraeian S (2004) Six-month magnetic resonance imaging follow-up of large and massive rotator cuff repairs reinforced with porcine small intestinal submucosa. J Shoulder Elbow Surg 13: 538-541. [Crossref]

10. Soler JA, Gidwani S, Curtis MJ (2007) Early complications from the use of porcine dermal collagen implants (Permacol) as bridging constructs in the repair of massive rotator cuff tears: a report of 4 cases. Acta Orthop Belg 73: 432-436. [Crossref]

11. Badhe SP, Lawrence TM, Smith FD, Lunn PG (2008) An assessment of porcine dermal xenograft as an augmentation graft in the treatment of extensive rotator cuff tears. $J$ Shoulder Elbow Surg 17: 35S-39S. [Crossref]

12. Lee DK (2007) Achilles tendon repair with acellular tissue graft augmentation in neglected ruptures. J Foot Ankle Surg 46: 451-455. [Crossref]

13. Lee DK (2008) A preliminary study on the effects of acellular tissue graft augmentation in acute Achilles tendon ruptures. J Foot Ankle Surg 47: 8-12. [Crossref]

14. Kokkalis ZT, Zanaros G, Weiser RW, Soter-eanos DG (2009) Trapezium resection with suspension and interposition arthroplasty using acellular dermal allograft for thumb carpo-metacarpal arthritis. J Hand Surg Am 34: 1029-1036. [Crossref]

15. Kokkalis ZT, Zanaros G, Sotereanos DG (2009) Ligament reconstruction with tendon interposition using an acellular dermal allograft for thumb carpometacarpal arthritis. Tech Hand Up Extrem Surg 13: 41-46. [Crossref]

16. Bond JL, Dopirak RM, Higgins J, Burns J, Snyder SJ (2008) Arthroscopic replacement of massive, irreparable rotator cuff tears using a GraftJacket allograft: technique and preliminary results. Arthroscopy 24: 403-409. [Crossref]

17. Wong I, Burns J, Snyder S (2010) Arthroscopic GraftJacket repair of rotator cuff tears J Shoulder Elbow Surg 19: 104-109. [Crossref]

18. Burkhead WZ, Schiffern SC, Krishnan SG (2007) Use of GraftJacket as an augmentation for massive rotator cuff tears. Semin Arthroplasty 18: 11-18.

19. Tornier announces launch of BioFiber Surgical Mesh for tendon repair at arthroscopic surgery conference. Tornier Press Release; April 14, 2011; Edina, MN, USA.

20. BioFiber Scaffold Post-Market Observational Study; June 20, 2017; Bethesda, MD, USA.

Copyright: (C2018 Hill W.This is an open-access article distributed under the terms of the Creative Commons Attribution License, which permits unrestricted use, distribution, and reproduction in any medium, provided the original author and source are credited. 